\title{
Plastic Bituminous Roads: A Sustainable Technology - For Better Handling Distresses
}

\author{
Arjita Biswas and Sandeep Potnis
}

\begin{abstract}
The present era, in particular, the last 3 to 4 decades can be easily named the "Plastic Age" and dealing with plastic waste has always been a challenging affair for Urban local bodies. Plastic roads are bituminous roads or pavement that have a waste plastic blended mix for their wearing courses. Plastic bituminous roads being a sustainable technology are becoming very popular nowadays as a substitute for conventional bituminous roads in India and other parts of the World. Evaluation of pavement is important to plan its maintenance strategy timely to avoid the complete deterioration of the pavement. In the present study, plastic bituminous roads and normal bituminous roads are evaluated for their various distress parameters and are compared based on distress parameters over the years. This paper tries to answer a basic question of whether Plastic Bituminous Roads are definitely sustainable but are they also better in handling the distresses. The study has also revealed that plastic bituminous roads perform better in early deterioration as compared to normal bituminous roads which will encourage field professionals and Urban Local bodies to use this sustainable technology.
\end{abstract}

Keywords - Distress, Normal Bituminous Roads, Plastic Bituminous Roads, Sustainable.

\section{INTRODUCTION}

Good roads and connectivity to all locations are very important. Cities all over the world have similar infrastructure but a country's true richness lies in the way its villages and remote locations are taken care of. After construction, proper maintenance of these roads is of the utmost importance for the smooth functioning of traffic. The definition of road maintenance given by the Indian Roads Congress (IRC), says, "Routine work performed to upkeep pavement, shoulders and other facilities provided for road users, as nearly as possible in their constructed conditions under normal conditions of traffic and forces of nature" [1]. Maintenance is essential to get optimum service from the pavement structure during its life period.

But, if any real-life solution can be given, which can prevent the early distresses on roads like potholes, cracks, ruts, etc., then it will save crores of rupees plus effort and management needed for periodic maintenance. Many researchers and scientists are experimenting with different materials specifically on bituminous roads which are referred to as modified bituminous roads to make them more durable which will require lesser maintenance. In order to reduce the accrual of plastic waste material on mother earth and also

Submitted on December 10, 2021

Published on February 09, 2022.

Dr. Arjita Biswas, National Institute of Construction Management \& Research, Pune, India.

(e-mail: abiswas ${ }^{@}$ nicmar.ac.in) boost its use for enhancement of pavements, research has been carried out in recent years. Tests have been conducted in order to control this issue and also to decide if this plastic waste can be recycled and put to use gainfully in the development of pavements [2]. Experimentation conducted in some organizations shows that when plastic waste is added to hot aggregates, the plastic forms a fine layer over the entire mix. This kind of blend mixed with waste plastic results in invigorating higher strength, and protection from water along with improved functioning over a period of time [2]. The related experimentation has indicated that the waste plastic when added to hot aggregate will form a fine coat of plastic over the aggregate and then when a mix is produced with the binder, it is found to give higher strength, higher resistance to water and better performance over a period of time. Therefore, it is relevant to use waste plastic in the construction of roads. Including waste plastic as a material in the construction of roads can prove to be a boon in two ways: by delaying the distresses leading to better roads and also utilization of waste which otherwise is an environmental hazard.

\section{A. Plastic Bituminous Roads (PBR)}

A sight that is very common in both, the provincial territories, as well as metropolitan areas, is empty plastic sacks as well as other plastic garbage littering the roads and streets. This kind of garbage is also responsible for choking the drains. Plastic being non-biodegradable tends to block off the water which leads to stagnation and other cleanliness issues. Based on recent studies in the year 2020, that have been published, plastic waste is generated 400 Million Tonnes globally each year and also it is observed that plastics are not biodegradable and remain unaltered on the earth for a period of about 4,500 years [3]. As the population of the world increases, there is a rise in demand for food as well as essentials increasing the amount of plastic waste that is generated daily.

Waste plastic can replace $10 \%$ to $15 \%$ of bitumen and this replacement can save approximately Rs. 35000 to Rs. 45000 for every kilometre of width $3.75 \mathrm{M}$ of roads. Utilizing waste plastic in the construction of roads can eliminate plastic shrinkage cracking and reduce drying shrinkage of road surfaces [4]. Inspired by the success of plastic roads (using plastic waste in bituminous roads), many state governments and local agencies in India started showing interest in laying down roads using this methodology. To give proper

Prof. Dr. Sandeep Potnis, MIT World Peace University, Pune, India (e-mail: Sandeep.potnis ${ }^{@}$ mitwpu.edu.in) 
guidelines for the construction of such types of roads Indian Road Congress (IRC) came up with a special code IRC SP: 98 in the year 2013. The IRC SP:98- 2013 code has made the concept of using such waste plastic in the laying of bituminous roads more streamlined and thus encouraging many more organizations and agencies to implement this technique.

The technology to make the plastic mix for the construction of roads is an uncomplicated process consisting of the following four steps:

1. Plastic wastes such as plastic cups, hard and soft foams, laminated plastics as well as plastic carry bags need to be collected.

2. The collected material needs to be washed and cleaned.

3. The cleaned material needs to be shredded to a uniform size.

4. The final step is to melt the plastic waste at a temperature of $165^{\circ} \mathrm{C}$ and blend it with hot aggregates as well as bitumen to lay the road.

\section{B. Advantages of Plastic Bituminous Road}

A PBR that has been built solidly results in the following advantages [5]-[8]:

- Better resistant to water.

- There is no stripping.

- There are better bonding and holding of the blend, resulting in fewer potholes.

- The roads are better able to withstand loads.

- There is a significant drop in the total use of bitumen.

- Less rutting and ravelling as a result of a reduction in pores entirely.

- There is a significant lengthening in the life period of the road.

- Radiation such as UV has no impact on the roads.

\section{LITERATURE SURVEY}

During the study at the Centre for Transportation Engineering in the laboratories of Bangalore University, India, plastic was made use of as an additive in varying measures 0 to $12 \%$ by weight of bitumen [5]. The outcome of the laboratory experimentations revealed that by adding an amount of $8.8 \%$ plastic waste by weight of bitumen, there was a substantial improvement in desirable properties of the bituminous mix such as strength, fatigue life, stability, and others that were experienced even under adverse conditions such as waterlogging. Adding $8.0 \%$ by weight of waste plastic to the mix for preparing the modified bitumen resulted in a saving of $0.4 \%$ bitumen by weight of the mix. Chavan [9] stated when a plastic coating is used in aggregates utilized in the construction of roads, it results in enhanced performance of the roads. Because of the increased bonding as well as the larger contact area between the bitumen and the polymers, the binding of the waste plastic-coated aggregate and the bitumen are greatly enhanced. Moreover, the polymer coating also brings about a reduction in voids resulting in the elimination of moisture absorption. Gawande, 2013 has proven the economic viability of the use of PBR [10]. The everincreasing traffic results in deterioration of roads which reduce the life of roads. Plastic roads are a cure by delaying the deterioration of roads. Using this technology will result in a saving of millions of dollars by reducing the bitumen content and lesser maintenance.

A 2014 study reported that plastic polyvinyl chloride (PVC), a form of plastic that is extremely hazardous for the environment is being used to substitute the bitumen up to $3 \%$ to $5 \%$ to modify it in the production of a paving mix. The author experimented with several trials and his experimentation concluded that the PVC refuse can be used with safety only if it can be homogenously blended with the bitumen at $160{ }^{\circ} \mathrm{C}$. Two benefits were observed. One was that the strength and stability of the bitumen mix that was produced with the PVC pipe waste increased and the second one was that the pavements were found to be more resistant to permanent deformation [11]. India has constructed 1 lakh $\mathrm{km}$ of roads in 11 states making use of plastic products that were discarded. It was in the year 2015 that the revolution of using plastic waste in the construction of roads caught on after the Government of India made it mandatory. India being in the midst of a garbage crisis, this initiative is very much in keeping with the Swachh Bharat Abhiyan movement (Clean India movement) of the Government [12]. A report by World Economic Forum states that roads made from plastic waste are better able to withstand extreme weather conditions such as heat and floods in comparison to roads that are built conventionally [13].

\section{A. Plastic Roads outside India}

The technology developed by Dr. R. Vasudevan became popular across the globe and many countries have adopted plastic roads in different ways. In the country of Indonesia, similar techniques with plastic are being used to construct roads. An asphalt-plastic mix is used in many areas including Bekasi, Surabaya, Bali, Makassar, Solo, and others [14].

A Dutch company called Volkerwessels built plastic roads in an area called Zwolle which is in the north eastern part of the Netherlands for bicyclists. Al-Hadidy \& Yi-Qiu [15] quantified that by using $6 \%$ pyrolysis Low-Density Polyethylene (LDPE) flexible pavements with superior durability and performance can be built in China. Such pavements are also more economical as has been indicated by studies that are based on the utilization of pyrolysis LDPE. Kwabena et al. [16] studied the effects of a blend of waste thermoplastic polymers like high-density polyethylene (HDPE) and polypropylene (PP) in traditional AC-20 grade bitumen, in varying blends. In the case of HDPE, it was observed that the most compatible blend was found to be at $2 \%$ polymer loading and the most incompatible blend was found to be at $3 \%$ polymer loading. In the case of PP, the most improved as well as homogenous blend was obtained with the PP at 3\% polymer loading. In the country of Ghana, as per this study, bitumen modified with waste plastic has tremendous potential as another option for recycling waste plastic. Moreover, it is well suited as a novel binder that has been modified and which can be used for the construction of roads. Agyeman et al. [17] undertook a series of tests in the laboratory on various types of plastic waste from multiple industries in Ghana, for the possible utilization of materials used for constructing roads such as paver blocks, etc. The outcome of these studies showed that low, as well as high 
content plastic samples, had improved compressive strength in comparison to specimens that had no plastic. According to a news report in India Times in January 2019 [13], the United Kingdom gave the go-ahead to a trial worth Rs.14 crores to construct plastic-asphalt roads to manage the millions of tons of plastic waste that have been filling up the country's landfills. In the Netherlands, an attempt has been made to construct roads that are made only from plastic. The first such road they built was a bike path in Rotterdam. By making use of only waste plastic, the carbon footprint of the entire process will be reduced as no asphalt is used. A recent news report published by India Times, 2020 [14] stated that the United Kingdom has announced that it is willing to invest $£ 1.6$ million in trying to build plastic roads as a collaborative effort with an asphalt enhancement company. The technique used for this venture is the one developed by R. Vasudevan along with some other secret compounds that ensure the durability of the roads. Cities like London, Gloucester, and Durham are areas where this technology is being implemented. Indonesia has also used the same technology to construct plastic waste mix roads in some parts of the country.

Various works reported [2], [4], [5], [18], [19] have suggested that plastic roads have better durable quality compared to normal bituminous roads. Nevertheless, there are very few field studies on this matter that have been done and reported. Kwabena et al. [16] suggested that more research should be carried out to examine the long-term performance of road sections used with plastic modified bitumen to evaluate the effects on distresses such as cracking resistance, rutting, etc. under varying traffic conditions. As seen from the literature review, no study to compare the actual performance of NBR and PBR has been conducted and also whether PBR is better in resisting distresses are not explored. The same has been targeted by the present study.

\section{METHODS}

\section{A. Selection of Study Area}

The selection of the appropriate pavement section for carrying out detailed investigation and performance evaluation was dependent on the defined criteria.

- The study area selected is Pune city titled as, "the most liveable city in India" situated in the state of Maharashtra, India.

- All the 20 roads selected for the study, i.e., Normal Bituminous Roads (NBR) and bituminous roads mixed with $8 \%$ waste plastic which is commonly known as Plastic Bituminous Roads (PBR) were laid during the same period, namely, December 2016, and come under the jurisdiction of Pune Municipal Corporation (PMC).

- All the roads are city roads (Category-local streets) with low traffic volume in terms of Commercial Vehicle Per Day (CVPD) (Low CVPD:50 to 450).

\section{B. Evaluation of Pavement Distresses}

The functional state of pavement is either measured or indicated by surface distress. The condition of the pavement resulting from surface distress is considered very significant by the concerned authorities. Pavement distress data has been collected on the 20 road sections that have been specifically chosen. These roads are both NBR and PBR. The basic inventory data of NBR and PBR were collected when the roads were being laid. Name of the road with its length, width, and type (PBR or NBR), details of overlaying, i.e., thickness in mm, type of overlay and also the date on which it was laid were all noted. Five distress parameters were selected which are predominant for urban roads with bituminous surfaces. The distresses are cracking, ravelling, potholes, rut depth, and settlement. But after the study it was observed that none of the roads had a settlement issue, hence it was automatically removed from further calculations and analysis. Physical distress is identified, and a quantified visual assessment of distress is made according to IRC: 82-2015 [20].

The distress studies were carried out for three consecutive years (2017-2019). Distresses like pavement ravelling, cracking, potholes, and rut depth have been measured utilizing simple measuring instruments like tape and a scale, and the results, in turn, have been converted into percentages expressed as the total area of the pavement surface. Each road was considered into sub-sections of $50 \mathrm{~m}$ for distress calculations. The distresses considered are as follows:

\section{1) Cracking}

Cracking of bituminous surfacing is common distress seen on the majority of roads in India. Cracking is of various types:

\section{Hairline cracks}

Hairline cracks are present in a narrow area and their width is less than one $\mathrm{mm}$. These appear as short and fine cracks at close intervals on the surface.

\section{Alligator or Map cracks}

Alligator or map cracking is characterized as a series of interconnected cracks, having small irregular blocks in pavement surface which resemble the skin of an alligator. These cracks may be of different types depending upon the extent and severity. The size of irregular shape blocks of cracks varies from less than $30 \mathrm{~cm}$ to more. Fig. 1 below shows the alligator cracking at one NBR.

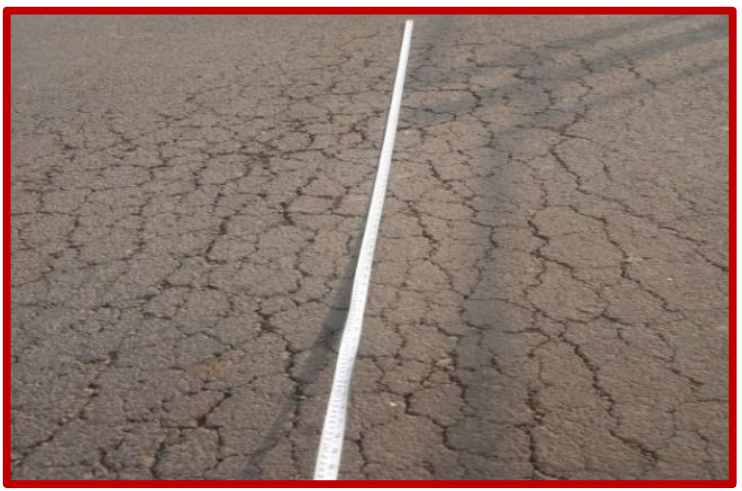

Fig. 1 Alligator cracking on NBR, Pune, India.

\section{Longitudinal cracks}

Cracks that appear parallel to the centerline or along the road are called longitudinal cracks.

\section{Transverse cracks}

These cracks appear in the transverse directions or as interconnected cracks forming series of large blocks perpendicular to the direction of the road.

\section{Edge Cracks}

Edge cracking is defined as cracks that develop parallel to the outer edge of the pavement. 
IRC:82-2015 states at the network level all the different types of cracking can be consigned under percentage cracking. The study has considered all the different types of cracking as cracking percentages.

\section{2) Ravelling}

Ravelling is defined as progressive separation and dissociation of fine aggregates particles and binder from the bituminous surface. Fine aggregates wear away first followed by coarse aggregates. The ravelling process generally starts from the surface and goes down or starts from the edge and goes inward. Fig. 2 below shows the ravelling on one of the NBR.

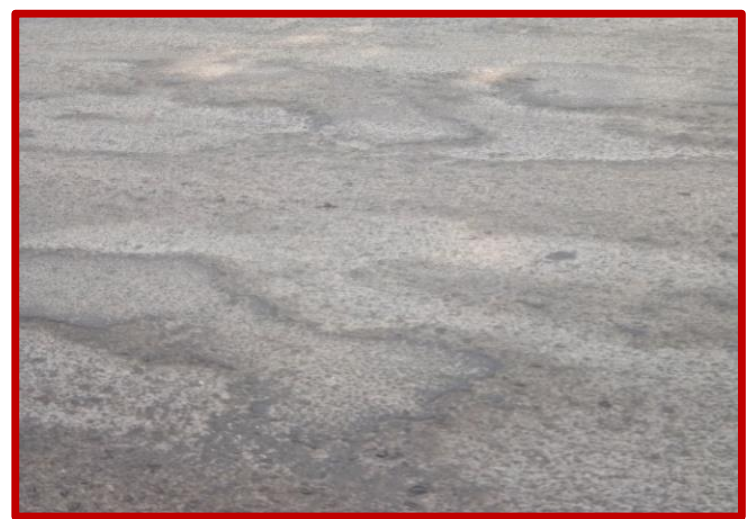

Fig. 2. NBR showing ravelling condition, Pune, India.

\section{3) Potholes}

Bowl-shaped cavities of differing sizes in the bituminous surface of the road or extending into the binder or the base course of the pavement are known as potholes. They are caused by localized disintegration of the mix that is used to build the road. The most common cause of pothole formation is loss of adhesion in bituminous wearing coat due to the ingress of water into the pavement or due to higher voids in the surface. Fig. 3 shows the formation of a pothole on one of the PBR.

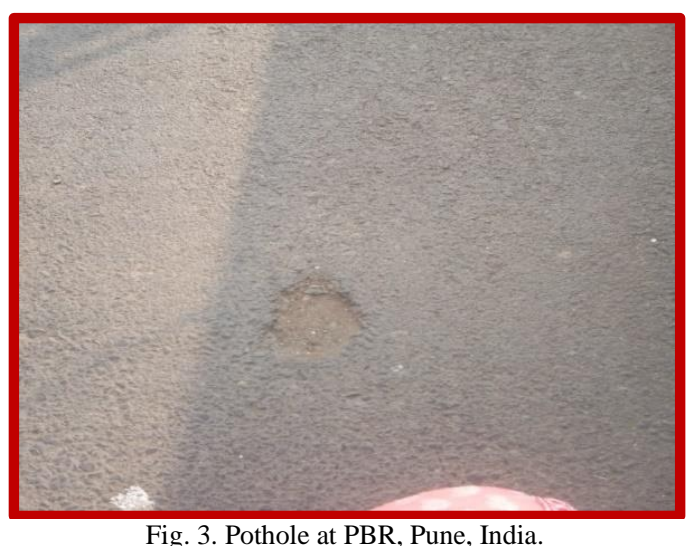

\section{4) Rutting}

Rutting is a result of longitudinal displacement in the path of the wheel as a result of the wheel load. Rutting has also been examined in the current study and the average rut depth has been measured utilizing a 3-metre straight edge with a procedure that has been followed as per IRC: 82-2015 guidelines [20].

After evaluating distresses, the next objective was to assess how the roads are behaving over the years and whether PBR is better in resisting distress. For that 2 -Way ANOVA would be the best statistical tool.

\section{Two Way Analysis of Variance (2-way ANOVA)}

"A 2-way ANOVA tests the effect of two independent variables on a dependent variable". In statistics, the two-way analysis of variance (ANOVA) is an extension of the one-way ANOVA that examines the influence of two different categorical independent variables on one continuous dependent variable. The two-way ANOVA not only aims at assessing the main effect of each independent variable but also if there is any interaction between them.

The benefits of Two-Way ANOVA are:

- It is more accurate to simultaneously analyse two variables rather than separately.

- By adding a second factor that is assumed to affect the response, the residual variance in a model can be minimized.

- The interactions between factors can be investigated.

Since the primary objective of the study is to find out "how the roads (PBR and NBR) are performing over the years" and "whether there is a significant difference between normal roads and plastic roads", 2-way ANOVA is considered most suited. Aflaki Sassan [21] applied two-way ANOVA to investigate the effects of crumb rubber modification (CRM) on bitumen's rheological properties as a performance grade (PG) improvement for medium, moderate, and high service temperatures. The author also looked into the effects of low/high shear blending conditions on rheological properties. Two-way ANOVA was used to investigate the impact of interactions between blending conditions and modifier material.

Ozge Karadas Atas gives the sample size for the ANOVA and the requirement given by the author fits the research data well [22]. Through this 2-way ANOVA, the researcher is trying to answer three research questions, namely:

- Whether PBR and NBR differ in different distress parameter conditions.

- Whether the distress condition differs across years.

- There are no interaction effects between the first and second factors.

The level is significant $(\alpha)$ is considered as $5 \%$ and $1 \%$ respectively. A significance level of 0.05 indicates a $5 \%$ risk of concluding that an effect exists when there is no actual effect.

All measurable estimations are calculated with the assistance of Statistical Product and Service Solutions (SPSS software). IBM-SPSS is a widely used program for statistical analysis in research works of all kinds. The IBM -SPSS programming offers progressed measurable investigation and effectively accessible programming and remarkable tool to perform 2-way ANOVA. SPSS Statistics version 13.0 has been used for the analysis of two-way ANOVA. The calculation for one distress is detailed and all other distresses are analysed in a similar manner.

\section{Research Question for Cracking Condition}

- Whether plastic road and normal road differ in different cracking conditions?

- Whether the cracking condition differs across years?

- Whether there are interaction effects between the 
Cracking Condition for plastic roads and normal roads across years?

\section{E. Variables and Measurement}

\section{1) Independent Variables}

Type of Roads

1. Plastic Bituminous Roads.

2. Normal Bituminous Roads.

Year of Distress evaluation

1. 2017.

2. 2018 .

3. 2019.

\section{2) Dependent Variable}

Cracking Condition in \% age

Hypothesis Development

A hypothesis is a testable proposition, that the researcher wants to examine. In this study, several hypotheses have been developed, which have been discussed below.

\section{3) Main Effect (1): Road Types}

Null Hypothesis $\left(\mathrm{H}_{01}\right)$ : PBR and NBR do not differ in cracking conditions.

Alternative Hypothesis $\left(\mathrm{Ha}_{1}\right)$ : PBR and NBR significantly differ in cracking conditions.

\section{4) Main Effect (2): Year}

$\mathrm{H}_{\mathrm{o} 2}$ : Cracking conditions do not differ across three years.

$\mathrm{Ha}_{2}$ : Cracking condition differs across three years.

\section{5) Interaction Effect (3): Year $\times$ Group}

Two-way ANOVA also examines the interaction effect of years and the type of roads put together.

The hypothesis to be tested for interaction effect are as follows:

$\mathrm{H}_{03}$ : No interaction Effect. (Interaction Effect absent).

$\mathrm{H}_{\mathrm{a} 3}$ : Interaction Effect Exist.
Table I present the basic descriptive statistics of the two types of roads across three years, 2017, 2018, 2019. It is evident from Table I that the average of plastic roads is quite lower compared to normal bituminous roads $(0.37$ compared to 0.54 ).

To test the hypothesis $\mathrm{H}_{01} \mathrm{H}_{02}$ and $\mathrm{H}_{03}$, 2-way ANOVA is performed. The results of 2-way ANOVA are presented in Table II.

TABLE IIII shows that cracking condition density differ significantly between PBR and NBR, as the reported significance value is less than $\alpha(0.000)$ at $5 \%$. Therefore, $\mathrm{H}_{01}$ is rejected and $\mathrm{H}_{\mathrm{a} 1}$ is accepted at a $5 \%$ level of significance. Similarly, with respect to years, the cracking condition density differs significantly across years (2017-2019). The reported significance value $0.000<\alpha$, i.e., 0.05 . Hence, the null hypothesis $\mathrm{H}_{02}$ is also rejected and $\mathrm{H}_{\mathrm{a} 2}$ is accepted which states cracking condition differs across three years. TABLE IIII shows that the significance of the interaction effect $(0.311)$ is more than $\alpha$, hence, we fail to reject $\mathrm{H}_{03}$. Therefore, it is concluded that the interaction effect is absent. It means as time passes both plastic and normal bituminous roads are deteriorating.

\section{6) Research question for Ravelling Condition}

Similarly, for Ravelling condition, several hypotheses were formulated, and results are shown below. It is evident from Table III that the average of plastic roads is quite lower compared to NBR (0.362 compared to 0.471). It is also observed in plastic roads for the first year, i.e., 2017, the value is zero which further proves the deterioration started late in the case of PBR.

In order to test the hypothesis $\mathrm{H}_{01} \mathrm{H}_{02}$ and $\mathrm{H}_{03}$, 2-way ANOVA is performed. The results of two-way ANOVA are presented in TABLE IV.

TABLE I: DESCRIPTIVE STATISTICS OF PBR AND NBR FOR CRACKING CONDITION

\begin{tabular}{|c|c|c|c|c|c|}
\hline Year & Mean & Std. Deviation & Year & Mean & Std. Deviation \\
\hline \multicolumn{3}{|c|}{ Plastic bituminous road } & \multicolumn{3}{|c|}{ Normal bituminous road } \\
\hline 2017 & 0.0790 & 0.14450 & 2017 & 0.0983 & 0.14122 \\
\hline 2018 & 0.2054 & 0.25863 & 2018 & 0.5119 & 0.61322 \\
\hline 2019 & 0.8246 & 0.66849 & 2019 & 1.0231 & 0.87418 \\
\hline Total & 0.3700 & 0.53034 & Total & 0.5444 & 0.72455 \\
\hline
\end{tabular}

TABLE II: AsSESSING SIGNIFICANCE FOR ROADS Vs GROUP FOR CRACKING CONDITION Tests of Between-Subjects Effects

\begin{tabular}{cccccc}
\hline \multicolumn{7}{c}{ Tests of Between-Subjects Effects } \\
\hline \multicolumn{7}{c}{ Dependent Variable: Cracking condition \%/ density } \\
Source & $\begin{array}{c}\text { Type III Sum of } \\
\text { Squares }\end{array}$ & Df & Mean Square & F & Sig. \\
\hline Corrected Model & 29.360 & 5 & 5.872 & 19.171 & $000^{* *}$ \\
Intercept & 42.928 & 1 & 42.928 & 140.151 & $000^{* *}$ \\
Group & 1.563 & 1 & 1.563 & 5.101 & $0.025^{*}$ \\
Year & 24.861 & 2 & 12.431 & 40.584 & $000^{* *}$ \\
Group X Year & 0.720 & 2 & 0.360 & 1.176 & 0.311 \\
Error & 64.323 & 210 & 0.306 & & \\
\hline
\end{tabular}

*Significant at 5\%.**Significant at $1 \%$.

TABLE III: DESCRIPTIVE STATISTICS OF P.B.R AND N.B.R FOR RAVELLING CONDITION

\begin{tabular}{cccccc}
\hline Year & Mean & Std. Deviation & Year & Mean & Std. Deviation \\
\hline & Plastic bituminous road & & Normal bituminous road \\
\hline 2017 & 0.0000 & 0.0000 & 2017 & 0.03516 & 0.12065 \\
2018 & 0.2585 & 0.64210 & 2018 & 0.31880 & 0.53875 \\
2019 & 0.8277 & 1.13551 & 2019 & 1.05945 & 1.45820 \\
Total & 0.3621 & 0.82132 & Total & 0.47114 & 0.99293 \\
\hline
\end{tabular}


TABLE IV: ASSESSING SIGNIFICANCE FOR ROADS VS GROUP FOR RAVELLING CONDITION

\begin{tabular}{cccccc}
\hline \multicolumn{7}{c}{ Tests of Between-Subjects Effects } \\
\hline Source & $\begin{array}{c}\text { Type III Sum of } \\
\text { Squares }\end{array}$ & Df & Mean Square & F & Sig. \\
\hline Corrected Model & 35.267 & 5 & 7.053 & 9.843 & $0.000^{* *}$ \\
Intercept & 35.641 & 1 & 35.641 & 49.736 & $0.000^{* *}$ \\
Group & 0.610 & 1 & 0.610 & 0.851 & 0.357 \\
Year & 31.028 & 2 & 15.514 & 21.649 & $0.000^{* *}$ \\
Group x Year & 0.391 & 2 & 0.196 & 0.273 & 0.761 \\
Error & 150.487 & 210 & 0.717 & & \\
\hline
\end{tabular}

*Significant at $5 \%$. **Significant at $1 \%$.

TABLE V: DESCRIPTIVE STATISTICS OF P.B.R AND N.B.R FOR POTHOLES CONDITION

\begin{tabular}{cccccc}
\hline Year & Mean & Std. Deviation & Year & Mean & Std. Deviation \\
\hline \multicolumn{3}{r}{ Plastic bituminous road } & \multicolumn{3}{c}{ Normal bituminous road } \\
\hline 2017 & 0.0009 & 0.00504 & 2017 & 0.0032 & 0.01202 \\
2018 & 0.01433 & 0.05648 & 2018 & 0.0698 & 0.24627 \\
2019 & 0.0619 & 0.17524 & 2019 & 0.2284 & 0.41028 \\
Total & 0.0257 & 0.10830 & Total & 0.1005 & 0.29017 \\
\hline
\end{tabular}

TABLE VI: AsSESSING SIGNIFICANCE FOR ROADS VS GROUP FOR POTHOLES CONDITION

Tests of Between-Subjects Effects

\begin{tabular}{|c|c|c|c|c|c|}
\hline \multicolumn{6}{|c|}{ Dependent Variable: Potholes condition \%/ Density } \\
\hline Source & $\begin{array}{c}\text { Type III Sum of } \\
\text { Squares }\end{array}$ & Df & Mean Square & $\mathrm{F}$ & Sig. \\
\hline Corrected Model & 1.522 & 5 & 0.304 & 5.936 & $0.000 * *$ \\
\hline Intercept & 0.818 & 1 & 0.818 & 15.956 & $0.000 * *$ \\
\hline Group & 0.287 & 1 & 0.287 & 5.598 & $0.019 *$ \\
\hline Year & 0.746 & 2 & 0.373 & 7.273 & $0.001 * *$ \\
\hline Group x Year & 0.240 & 2 & 0.120 & 2.342 & 0.099 \\
\hline Error & 10.769 & 210 & 0.051 & & \\
\hline
\end{tabular}

*Significant at $5 \%$. **Significant at $1 \%$.

TABLE IV shows that ravelling condition density differs significantly between PBR and NBR, as the reported significance value $(0.357)$ is more than $\alpha$ at $5 \%$. Therefore, $\mathrm{H}_{01}$ is accepted. Hence, it is concluded that plastic and normal bituminous roads do not differ in ravelling conditions. Similarly, with respect to years, the ravelling condition density differs significantly across years (2017-2019). The reported significance value $0.000<\alpha$, i.e., 0.05 . Hence, the null hypothesis $\mathrm{H}_{02}$ is also rejected and $\mathrm{H}_{\mathrm{a} 2}$ is accepted which states ravelling condition differs across three years. Table IV also shows that the significance for interaction effect $(0.761)$ is more than $\alpha$, hence, we fail to reject the $\mathrm{H}_{03}$. Therefore, it is concluded that the interaction effect is absent. It means as time passes both plastic and normal bituminous roads are deteriorating in terms of ravelling conditions.

\section{7) Research question for Potholes Condition}

Similarly, for the condition of the pothole, several hypotheses were formulated, and the results are shown below. TABLE V presents the basic descriptive statistics of the two types of roads across three years, 2017, 2018, 2019 for potholes. It is evident from TABLE V that the average of PBR is quite lower compared to NBR (0.02574 compared to
0.1005). It is also observed in plastic roads for the first year i.e., 2017, the value is negligible which further proves the deterioration started late in the case of PBR.

To test the hypothesis $\mathrm{H}_{01} \mathrm{H}_{02}$ and $\mathrm{H}_{03}$, 2-way ANOVA is performed. The results of 2-way ANOVA are presented in TABLE VI.

TABLE VI shows that pothole's condition density differs between PBR and NBR, as the reported significance value $(0.019)$ is less than $\alpha$ at $5 \%$. Therefore, $\mathrm{H}_{01}$ is rejected. Hence, it is concluded that PBR and NBR differ in potholes condition. Similarly, with respect to years, the potholes' condition density differs significantly across years (20172019). The reported significance value $0.001<\alpha$, i.e., 0.05 . Hence, the null hypothesis $\mathrm{H}_{02}$ is also rejected and $\mathrm{H}_{\mathrm{a} 2}$ is accepted which states potholes condition differs across three years.

\section{8) Research Question for Rut Depth Condition}

To test the hypothesis $\mathrm{H}_{01} \mathrm{H}_{02}$ and $\mathrm{H}_{03}$, 2-way ANOVA is performed. The results of 2-way ANOVA are presented in Table VIII.

TABLE VII: DESCRIPTIVE STATISTICS OF PBR AND NBR FOR RUT DEPTH CONDITION

\begin{tabular}{cccccc}
\hline Year & Mean & Std. Deviation & Year & Mean & Std. Deviation \\
\hline & Plastic bituminous road & \multicolumn{3}{c}{ Normal bituminous road } \\
\hline 2017 & 0.0000 & 0.00000 & 2017 & 0.0000 & 0.00000 \\
2018 & 0.0000 & 0.00000 & 2018 & 0.0025 & 0.01718 \\
2019 & 0.0825 & 0.20827 & 2019 & 0.0168 & 0.07873 \\
Total & 0.0275 & 0.12507 & Total & 0.0064 & 0.04676 \\
\hline
\end{tabular}


TABLE VIII: ASSESSING SIGNIFICANCE FOR ROADS VS GROUP FOR RUT DEPTH CONDITION

\begin{tabular}{cccccc}
\hline \multicolumn{6}{c}{ Tests of Between-Subjects Effects } \\
\hline \multicolumn{5}{c}{ Dependent Variable: Rut depth condition \% / density } \\
\hline Source & $\begin{array}{c}\text { Type III Sum of } \\
\text { Squares }\end{array}$ & Df & Mean Square & F & Sig. \\
\hline Corrected Model & 0.157 & 5 & 0.031 & 4.549 & $0.001^{* *}$ \\
Intercept & 0.059 & 1 & 0.059 & 8.583 & $0.004^{* *}$ \\
Group & 0.023 & 1 & 0.023 & 3.291 & 0.071 \\
Year & 0.110 & 2 & 0.055 & 7.945 & $0.000^{* *}$ \\
Group x Year & 0.051 & 2 & 0.026 & 3.713 & $0.026^{*}$ \\
Error & 1.451 & 210 & 0.007 & & \\
\hline *Significant at 5\% **Significant at 1\%
\end{tabular}

Table VII presents the basic descriptive statistics of the two types of roads across three years. It is observed from TableVII that in the first year both the types of roads (NBR and PBR) have no rut depth which is a good sign in itself which signifies both the roads are extremely safer in terms of driving safety as the main concern with rutting has been related to driving safety. It is also observed in 2018, PBR has not developed any rutting which further proves in the initial year PBR is developing no distresses in terms of rut depth. Mean rut depth is more in PBR which is due to one road where it is coming significantly high. Physical verification of that specific road has revealed that there is construction work at the adjacent site because of which heavily loaded trucks are continuously plying which may be the reason for the increased rut depth in that particular road.

\section{DISCUSSION AND CONCLUSION}

The results obtained from basic descriptive statistics of the two types of roads across three years for cracking, potholes and ravelling condition reveal that mean distress over the years is always more in the case of NBR as compared to PBR which further proves PBR is good in resisting early distress. Mean rut depth is more in PBR and the reason is already stated in the previous section of the paper. The study has also revealed that plastic and normal bituminous roads differ in cracking and potholes conditions whereas they do not differ in ravelling conditions. Plastic and Normal bituminous roads significantly differ in rut depth conditions.

The use of this sustainable and innovative technology not only reinforced road construction but also increased road life by resisting early distresses and indirectly saving the costly bitumen by replacing it with waste plastic. With the use of waste plastic in roads, it is expected that India will have strong, durable, and eco-friendly roads in the near future, relieving the country of all types of plastic waste.

\section{REFERENCES}

[1] Indian Road Congress (IRC). Guidelines for the Use of Waste Plastic in Hot Bituminous Mixes (Dry Process) in Wearing Course IRC SP:982013, New Delhi, India: Indian Road Congress (IRC), 2013.

[2] Vasudevan R, Saravanavel S., Rajesekaran S., Thirunakkarasu D. Reuse of waste plastics for road laying. Indian Highways, Indian Road Congress, 2006:5-20.

[3] Ali Chamas, Hyunjin Moon, Jiajia Zheng et al. Degradation Rates of Plastics in the Environment. ACS Sustainable Chemistry and Engineering, Feb 2020:3494-3511.

[4] Vasudevan R, ARC Sekar, B Sundarakannan, R Velkennedy. A technique to dispose waste plastics in an ecofriendly way-Application in construction of flexible pavements. Construction and Building Materials, 2012:311-320.
[5] Gawande Amit., Zamre G., Renge V. C. \& Bharsakale G. R. Utilization of waste plastic in Asphalting of Roads- A Review. Scientific Reviews and Chemical Compositions, 2012:147-157.

[6] Mehmood R. \& Bajaj., M. Performance Evaluation of utilization of wastepolythelene teraphthalate as a asphalt modifier in asphalt cocrette mix. International Journal of Scientific Development and Research (IJSDR), 2018:294-298.

[7] Biswas Arjita, Goel A., Potnis S. Performance Evaluation of Sustainable bituminous- Plastic roads for Indian conditions, International Journal of Engineering and Advanced Technology, 2019;9:63834-6392.

[8] Biswas Arjita, Goel A., Potnis S. Performance comparison of waste plastic modified versus conventional bituminous roads in Pune city: A case study. Case Studies in Construction Materials, Elsevier, 2020:19.

[9] Chavan A. Use of plastic waste in flexible pavements. International Journal of Application or Innovation in Engineering and Management, 2013: 540-551.

[10] Gawande Amit. Economics and Viability of Plastic Road: A Review. Journal of Current Chemical and Pharmacuetical Sciences, 2013:231 242.

[11] Behl Ambike, Sharma Girish; Kumar Gajendra. A sustainable approach: utilization of waste PVC in asphalting of roads. Construction Building Materials, 2014:113-117.

[12] https://swachhindia.ndtv.com/plastic-waste-roads-one-lakh-kilometreindia-20274.

[13] India Times, 2019. India Times.com. [Online] Available at: https://www.indiatimes.com/technology/news/[Accessed January 2019].

[14] Indiatimes, 2020. www.indiatimes.com. [Online] Available at: https://www.indiatimes.com/technology/science-and-future/meetpadma-shree-r-vasudevan-who-made-roads-stronger-with-wasteplastic-that-saves-our-planet.

[15] Al-Hadidy A. \& Yi-qiu T. Effect of polyethylene on life of flexible pavements. Construction and Building Materials, 2009:1456-1464.

[16] Kwabena A. J., Berko-Boatenga Victor Nana \& T. A. Use of waste plastic materials for road construction in Ghana. Case Studies in Construction Materials, 2016:1-7.

[17] Agyeman S., Obeng-Ahenkora N., Assiamah S. \& Twuimasi G. Exploiting recycled plastic waste as an alternative binder for paving blocks production. Case studies of Construction Materials, 2019:1-8.

[18] Sreedevi B. G. and Salini P. N. Use of waste plastics for road construction study on bituminous mixes, Proc. National Seminar on emerging trends in Environment', Org. by University of Kerala, 2009:295-302.

[19] Rajasekaran S., Vasudevan R., Samuvel P. Reuse of Waste Plastics Coated Aggregates-Bitumen Mix Composite for Road Application Green Method. American Journal of Engineering Research (AJER), 2013:1-13.

[20] IRC: SP 82-2015. Code of Practice for Maintenance of Bituminous Road Surface, New Delhi, India: Indian Road Congress(IRC), 2015.

[21] Aflaki Sassan M. M. Using two-way ANOVA and hypothesis test in evaluating crumb rubber modification (CRM) agitation effects on rheological properties of bitumen. Construction and Building materials, 2011: 2094-2106.

[22] Ozge Karadas Atas, S. A. A. Optimal Sample Size Determination for the ANOVA Designs. International Journal of Applied Mathematics and Statistics, 2011:127-134. 